\title{
A GoOD Sign FOR Multivariate RisK TAKING
}

\author{
LOUIS EECKHOUDT \\ BÉATRICE REY \\ HARRIS SCHLESINGER
}

CESIFO WORKING PAPER NO. 1796

CATEGORY 10: EMPIRICAL AND THEORETICAL METHODS

SEPTEMBER 2006

\footnotetext{
An electronic version of the paper may be downloaded

- from the SSRN website: Www.SSRN.com

- from the RePEc website: Www.RePEc.org

- from the CESifo website: www.CESifo-group.de
} 


\title{
A GOOD Sign FOR MULTIVARIATE RISK TAKING
}

\begin{abstract}
Decisions under risk are often multidimensional, where the preferences of the decision maker depend on several attributes. For example, an individual might be concerned about both her level of wealth and the condition of her health. Many times the signs of successive cross derivatives of a utility function play an important role in these models. However, there has not been a simple and intuitive interpretation for the meaning of such derivatives. The purpose of this paper is to give such an interpretation. In particular, we provide an equivalence between the signs of these cross derivatives and individual preference within a particular class of simple lotteries.
\end{abstract}

JEL Code: D81.

Keywords: correlation aversion, multivariate risk, prudence, risk aversion, temperance.

\author{
Louis Eeckhoudt \\ Catholic University of Mons, FUCaM \\ 151 Chaussée de Binche \\ 7000 Mons \\ Belgium \\ louis.eeckhoudt@fucam.ac.be
}

\author{
Béatrice Rey \\ ISFA, University of Lyon 1 \\ 50 avenue Tony Garnier \\ 69007 Lyon \\ France \\ beatrice.rey-fournier@univ-lyon1.fr
}

\author{
Harris Schlesinger \\ Department of Economics and Finance \\ University of Alabama \\ Tuscaloosa, AL 35487-0224 \\ USA \\ hschlesi@cba.ua.edu
}

April 20, 2006

The authors thank participants at the World Risk and Insurance Economics Congress and at INSEAD, as well as Christophe Courbage, Marc Fleurbaey and three referees for helpful comments. 


\section{Introduction}

Decisions often have multidimensional consequences with some, if not most, of them being risky. Health insurance - whether private or public - is a good example. Individuals pay insurance premia and/or taxes that affect their level of wealth in order to receive medical treatment in case of illness. Thanks to this treatment, they usually have improved health, although such treatment is not without risk. The insurance program affects both the wealth and the health of the policyholder.

There are many other settings for such multidimensional consequences as well. For example, consider an intertemporal model in which preferences depend on the lifetime path of consumption. An individual must face various trade-offs between the levels and the riskiness of consumption in successive time periods, thus presenting the individual with a multidimensional decision. Labor economics also provides many examples of multidimensional decision making under risk. In addition, the same techniques used in such a decision context can be applied to analyzing multidimensional distributions of economic status within the literature on income distribution.

Ever since the paper by Eisner and Strotz (1961), the literature on choices under risk with multidimensional utilities has shown time and again that the signs of successive cross derivatives of the utility function play an important role. For example, if the sign of a certain derivative remains unchanged over its domain, it sometimes leads to necessary or to sufficient conditions for various comparative-static results.

While the comparative-static results themselves usually have some economic interpretation, so far there is no simple and intuitive interpretation for the signs of such derivatives on their own. What exactly does it imply when we assume that one of these cross derivatives is always positive or is always negative? The purpose of this paper is to give such an interpretation.

To accomplish our goal, we first define a preference ordering over a set of simple lotteries. We start by reviewing the concept of "correlation aversion" 
as defined by Epstein and Tanny (1980). ${ }^{1}$ We extend this lottery preference to allow for multiple-dimension analogues of prudence and temperance, which we label as "cross prudence" and "cross temperance." This follows along lines suggested by Eeckhoudt and Schlesinger (2006) in one dimension. We then show how these particular lottery preferences are equivalent to signing the cross derivatives if we use an expected-utility framework for our analysis.

More specifically, we postulate two basic types of "harms" for someone with preferences that are both monotonic and risk averse in each dimension. In particular, such an individual will dislike a reduction in any attribute, ceteris paribus. This individual also will dislike the introduction of a zeromean risk added to any attribute, assuming that the risk is independent of other risks inherent in these attributes. For instance, an individual might have such preferences over monetary wealth and some objective measure of health, such as the individual's own longevity. It is the interaction of these types of harms upon one's preferences that determine whether preferences exhibit "correlation aversion" or "cross prudence" or "cross temperance."

We begin in the next section with a brief overview of some of the existing literature for which the results are dependent upon the signs of various cross derivatives of multidimensional utility functions. We next define our simple lottery preferences. These preferences are then shown to be equivalent to assuming particular signs for various cross derivatives of the utility function when used in an expected utility framework. Our main tool of analysis is the "utility premium," as defined by Friedman and Savage (1948), which in a certain sense measures the level of "pain" associated with taking a particular risk and thus turns out to be particularly appropriate in determining how various harms either exacerbate or mitigate one another when taken in tandem. We then present some applications of the results to specific problems within an intertemporal-choice framework. Our concluding remarks focus on

\footnotetext{
${ }^{1}$ To the best of our knowledge, this concept first appeared in de Finetti (1952). It was brought into the economic literature, though under different terminology, by Richard (1975).
} 
the applicability of our results.

\section{Some Multivariate Models}

Our goal in this section is not to present a complete survey of the literature of multivariate risk taking, which is quite large, but rather to give a sample of the types of results that appear in the extant literature. To the best of our knowledge, one of the first papers to discuss the sign of the cross derivative of the utility function was by Eisner and Strotz (1961), who analyzed the demand for flight insurance. They remarked how the sensitivity of marginal utility of wealth to a nonpecuniary variable is quite relevant in many areas, such as health insurance and flight insurance for example. Their observation provides an introduction to the notion of "correlation aversion," that will be discussed in the next section.

In the area of labor economics, papers by Eaton and Rosen (1980) and by Tressler and Menezes (1980) discuss the impact of wage uncertainty and of taxation on the supply of labor. Comparative-static results in both of these papers require that one be able to sign the third cross derivative of a utility function. As we show later in the paper, signing this cross derivative is equivalent to a particular lottery preference and to a concept we label as "cross prudence."

Rather similar results are found in the literature on health economics. In a paper on the demand for medical care, Dardanoni and Wagstaff (1990) use a utility function that depends upon consumption and health status. They show how the demand for care depends on the signs of both the second and third cross derivatives of the utility function. ${ }^{2}$ A recent paper by Bleichrodt, et al. (2003) models the effects of comorbidities on medical-treatment decisions and shows that the sign of the fourth cross derivative of utility plays

\footnotetext{
${ }^{2}$ They also show how the signs of the second and third own derivative matter as well. It is interesting to note that Dardanoni (1988) published an earlier paper of a more general nature, dealing with "two-argument utility functions."
} 
a role in analyzing the optimal decisions. We show in the next section how signing these cross derivatives is once again equivalent to a particular lottery preference that we label as "cross-temperance."

One also can view the vast literature on intertemporal consumption and savings decisions as belonging to the class of multivariate risk taking models, where lifetime utility depends upon the vector of lifetime consumption flows. Early papers by Leland (1968), Sandmo (1970) and Drèze and Modigliani (1972) examined how the demand for savings reacts to income risk and interest-rate risk. Indeed, the authors noted how their results were dependent, in part, to how risk aversion with respect to one argument of the utility function (for example, future consumption) reacted to a change in another argument (for example, current consumption). Although we do not discuss their cross derivatives directly here, we show in section 5 how several intertemporal decisions, based on multivariate preference within each period, can be modelled directly.

Finally, we note that the concepts referred to here in the context of analyzing consumer choice under multivariate risk have an applicability to the large literature on multidimensional income inequality. In an important paper focussed on the distribution of "economic status," Atkinson and Bourguignon (1982) show again how many results depend upon the cross derivative of the welfare function, up to a third order. Many refinements and applications in this area continue to depend on the signs of such cross derivatives. ${ }^{3}$

\section{$3 \quad$ Lottery Preference}

We restrict the analysis here to bivariate preferences. The analysis can apply to higher dimensions by fixing all but two of the attribute levels. Let $(x, y) \in$ $\mathbb{R}_{+}^{2}$ denote a nonnegative vector of attributes. For the sake of concreteness,

\footnotetext{
${ }^{3}$ The literature is too large to give a complete set of references, but the papers by Wagstaff, et al. (1991), Moyes (1999) and Trannoy (2005) are good examples.
} 
will interpret the variable $x$ as wealth and $y$ as health, although certainly numerous other interpretations are possible. We assume that both higher levels of wealth and higher levels of health are preferred. Here health is measured by some objective measure, such as longevity. We also assume that the individual is risk averse in each dimension separately. Given a random wealth $\widetilde{x}$, the individual would prefer $E \widetilde{x}$ to $\widetilde{x}$ for every accompanying health level $y$. The same is assumed to hold if we reverse the roles of $x$ and $y$.

\subsection{Correlation Aversion}

Let $k$ and $c$ be arbitrary positive constants. Define an individual as being correlation averse if the lottery $[(x-k, y) ;(x, y-c)]$ is preferred to the lottery $[(x, y) ;(x-k, y-c)]$ for all $(x, y) \in \mathbb{R}_{+}^{2}$ such that $x-k>0$ and $y-c>0$. In this lottery, as well as all other simple lotteries in this paper, we assume that each outcome of the lottery has an equally likely chance of occurrence.

In other words, someone is correlation averse if he or she always prefers a 50-50 gamble of a loss in wealth or a loss in health over another 50-50 gamble offering a loss in neither dimension or a loss in both. This concept was first introduced by Richard (1975), although he used a different terminology, and was explored further by Epstein and Tanny (1980) in a setting where $x$ and $y$ denote consumption levels in two consecutive time periods.

For a correlation-averse individual, a higher level of health mitigates the detrimental effect of a reduction in wealth. Given the lottery $[(x, y) ;(x, y-c)]$ and being told that one must reduce wealth to level $x-k$, but only for one realization of the lottery, this individual would rather reduce wealth in the state of the world in which health is better. Note that the roles of wealth and health are completely arbitrary here and that we obtain the same characterization if they are switched.

We will call an individual correlation loving if the preference ordering for the above lotteries is always reversed. Obviously, either one of these assumptions is quite strong and an individual need not exhibit either of 
these traits. We make no normative claim here about an individual's being correlation averse. For example, a rational individual might decide that money is less valuable if he or she is not healthy enough to enjoy it. To such an individual, wealth and health behave like complements, and such an individual is correlation loving. On the other hand, money and health might behave as substitutes. Indeed someone in ill health might feel that money is more useful at the margin, since it can used in bettering the quality of life.

\subsection{Cross Prudence and Cross Temperance ${ }^{4}$}

Now let $\widetilde{\varepsilon}$ be an arbitrary zero-mean wealth random variable. We will say that an individual is cross prudent in health if the lottery $[(x+\widetilde{\varepsilon}, y) ;(x, y-c)]$ is preferred to the lottery $[(x, y) ;(x+\widetilde{\varepsilon}, y-c)]$ for all $(x, y) \in \mathbb{R}_{+}^{2}$ such that $y-c>0$ and $\operatorname{Supp}[x+\widetilde{\varepsilon}] \subseteq \mathbb{R}_{+} \cdot{ }^{5}$ For such an individual, a higher level of health mitigates the detrimental effect of the monetary risk $\widetilde{\varepsilon}$. Given the lottery $[(x, y) ;(x, y-c)]$ and being told that one must add the risk $\widetilde{\varepsilon}$ to wealth level $x$, but only for one realization of the lottery, this individual would rather add the harm $\widetilde{\varepsilon}$ in the state of the world in which health is better, $y$ rather than $y-c$.

In a similar manner, let $\widetilde{\delta}$ be an arbitrary zero-mean health random variable. An individual is cross prudent in wealth if the lottery $[(x, y+\widetilde{\delta}) ;(x-$ $k, y)]$ is preferred to the lottery $[(x, y) ;(x-k, y+\widetilde{\delta})]$ for all $(x, y) \in \mathbb{R}_{+}^{2}$ such that $x-k>0$ and $\operatorname{Supp}[y+\widetilde{\delta}] \subseteq \mathbb{R}_{+}$. For such an individual, higher wealth helps to temper the detrimental effects of accepting the health risk $\widetilde{\delta}$.

If either of the above sets of lottery preferences is always reversed, then we will refer to individual preferences as being cross imprudent in either wealth or health. For example, to someone who is cross imprudent in wealth,

\footnotetext{
${ }^{4}$ The term "prudence," in a univariate setting, was originally coined by Kimball (1990), who showed how it equates to $u^{\prime \prime \prime}>0$. The term temperance was also coined by Kimball (1992).

${ }^{5}$ We take some liberty with the notation here. By $\operatorname{Supp}[x+\widetilde{\varepsilon}]$ we mean the support of the distribution function associated with the random variable $x+\widetilde{\varepsilon}$.
} 
a higher level of wealth makes the addition of the health risk even more aggravating.

Now assume that $\widetilde{\varepsilon}$ and $\widetilde{\delta}$ are statistically independent of one another. We define preferences as being cross temperate if the lottery $[(x+\widetilde{\varepsilon}, y) ;(x, y+\widetilde{\delta})]$ is preferred to the lottery $[(x, y) ;(x+\widetilde{\varepsilon}, y+\widetilde{\delta})]$ for all $(x, y) \in \mathbb{R}_{+}^{2}$ such that $\operatorname{Supp}[x+\widetilde{\varepsilon}] \times \operatorname{Supp}[y+\widetilde{\delta}] \subseteq \mathbb{R}_{+}^{2}$. To such an individual, the losses $\widetilde{\varepsilon}$ and $\widetilde{\delta}$ are "mutually aggravating," to borrow terminology from Kimball (1993). Note that such an individual prefers to disaggregate the two harmful risks $\widetilde{\varepsilon}$ and $\widetilde{\delta}$.

\subsection{A Lattice Structure}

It is useful to note that the above sets of lottery preferences can be generalized into a lattice structure. Consider the set of all possible harms as described here. These include the negative constants (i.e. $-c$ and $-k$ ) and the zeromean random variables $(\widetilde{\varepsilon}$ and $\widetilde{\delta})$ in the above analyses. Now define $\Lambda \equiv$ $\{\lambda, 0\}$ and $\Gamma \equiv\{\gamma, 0\}$, where $\lambda$ is either $-k$ or $\widetilde{\varepsilon}$, and $\gamma$ is either $-c$ or $\widetilde{\delta}$. Let $(a, b)$ and $(A, B) \in \Lambda \times \Gamma$ such that $x+a, x+A, y+b$ and $y+B$ are all nonnegative almost surely. We let " $\succsim "$ denote the weak preference relation of the individual. Since $x \succsim x+\lambda$ and $y \succsim y+\gamma$, we always have the ability to rank the consumer's preference between $x+a$ and $x+A$, and between $y+b$ and $y+B$. Note that the weak preference will be indifference in the case where $A=a$ and the case where $B=b$.

We now define the meet and join for $(x+a, y+b)$ and $(x+A, y+B)$. Without loss of generality, assume that $x+A \succsim x+a$. Then the join is defined as

$$
(x+a, y+b) \vee(x+A, y+B)=\left\{\begin{array}{l}
(x+A, y+B) \text { if } y+B \succsim y+b \\
(x+A, y+b) \text { if } y+b \succsim y+B
\end{array}\right.
$$


and the meet is defined as

$$
(x+a, y+b) \wedge(x+A, y+B)=\left\{\begin{array}{c}
(x+a, y+b) \text { if } y+B \succsim y+b \\
(x+a, y+B) \text { if } y+b \succsim y+B
\end{array} .\right.
$$

In other words, the join pairs the better wealth outcome with the better health outcome, whereas the meet pairs the worse wealth and health outcomes. Since individual was assumed to be both monotone increasing and risk averse in each dimension separately, our definitions in this section - correlation aversion, cross prudence and cross temperance - are analogous to saying that a 50-50 gamble between $(x+a, y+b)$ and $(x+A, y+B)$ is always weakly preferred to a 50-50 gamble between the meet and the join.

\section{Relation to Utility}

We now consider the case where the individual's preferences can be represented by a bivariate model of expected utility. We let $u(x, y)$ denote the utility function and let $u_{1}(x, y)$ denote $\partial u / \partial x$ and $u_{2}(x, y)$ denote $\partial u / \partial y$. We follow the same subscript convention for the functions $u_{11}(x, y)$ and $u_{12}(x, y)$ and so on. We assume that the partial derivatives required for any definition all exist. For any fixed value of $y$, we can apply the results of Eeckhoudt and Schlesinger (2006) directly to interpret $u_{111}>0$ and $u_{1111}<0$ as prudence in wealth and temperance in wealth respectively. Similarly, we can inter-

pret the signs of $u_{222}$ and $u_{2222}$ as equivalents to prudence and temperance in health.

Our main result in this paper extends such interpretations to the cross derivatives:

Proposition 1 The following equivalences hold:

(i) An individual is correlation averse if and only if $u_{12} \leq 0 \quad \forall x, y$

(ii) An individual is cross prudent in health if and only if $u_{112} \geq 0 \quad \forall x, y$

(iii) An individual is cross prudent in wealth if and only if $u_{122} \geq 0 \quad \forall x, y$ 
(iv) An individual is cross temperate if and only if $u_{1122} \leq 0 \quad \forall x, y$.

We make no normative claim here as to whether or not individuals exhibit any or all of the above properties. ${ }^{6}$ We also make no claim as to whether or not expected utility is an appropriate model of consumer preference. For example, given a 50-50 gamble between adding a (zero-mean) risk in either health or wealth or a 50-50 chance of adding the risks to both health and wealth or not adding any risks at all, it might be the case that the individual sometimes chooses the later. This would imply that either $u_{1122}(x, y)>0$ at some values of $(x, y)$ or that expected-utility does not perfectly explain preferences. $^{7}$

We should note that numerous examples exist with cross derivatives exhibiting the signs in Proposition 1, as well as examples with exactly opposite signs. For example, $u(x, y)=-x^{-\alpha} y^{-\beta}$, with $\alpha>0$ and $\beta>0$, agrees with all of the signs in Proposition 1. On the other hand $u(x, y)=x^{\alpha} y^{\beta}$, with $(\alpha, \beta) \in(0,1) \times(0,1)$, has exactly the opposite signs. However, consider $u(x, y)=x y-\frac{1}{2} x^{2} y^{2}$, where we assume that wealth and health are scaled so that $0<x<1$ and $0<y<1$. This utility exhibits cross temperance but cross imprudence ( $u_{112}$ and $u_{122}$ are everywhere negative). Moreover, it exhibits correlation aversion only sometimes (if and only if $x y>\frac{1}{2}$ ). In addition, each of these utility functions exhibits the desirable unidirectional

\footnotetext{
${ }^{6}$ For example, in a very well scrutinized paper, Viscusi and Evans (1990) analyzed data from workplace injuries and found evidence that the sign of $u_{12}$ is positive, which of course would imply that correlation aversion does not hold in their model. However, in Evans and Viscusi (1991) they limited their evidence to minor injuries and found that $u_{12}$ is almost always negative in this case.

If the sign of $u_{12}$ is not uniform throughout the relevant range, then for fixed values of $c$ and $k$, neither 50-50 lottery, $[(x-k, y) ;(x, y-c)]$ or $[(x, y) ;(x-k, y-c)]$, is always preferred over the other for all $x, y$.

${ }^{7}$ One example of the latter might be a case in which cross temperance holds when $\widetilde{\varepsilon}$ and $\widetilde{\delta}$ are roughly of equal size (e.g. have the same variance), but does not hold if one of the random variables is "small" compared to the other. Perhaps such an individual puts a significant weight on the 50 percent probability of having no risk at all.
} 
properties: $u_{1}>0, u_{2}>0, u_{11}<0$ and $u_{22}<0 .{ }^{8}$

The remainder of this section provides proofs for the various cases of the above Proposition.

\subsection{Correlation Aversion}

The condition $u_{12} \leq 0 \forall(x, y)$ is equivalent to

$$
u(x, y-c)-u(x-k, y-c) \geq u(x, y)-u(x-k, y) \forall c, k \in \mathbb{R}_{++}^{2} .
$$

But rearranging and multiplying by $1 / 2$ shows that this is equivalent to

$$
\frac{1}{2}[u(x-k, y)+u(x, y-c)] \geq \frac{1}{2}[u(x, y)+u(x-k, y-c)]
$$

which is equivalent under expected utility to the lottery-preference definition of correlation aversion. ${ }^{9}$

\subsection{Cross Prudence}

For a fixed risk $\widetilde{\varepsilon}$, define $v(x, y) \equiv u(x, y)-E u(x+\widetilde{\varepsilon}, y)$. This is simply an analogue to the utility premium originally defined by Friedman and Savage (1948). It indicates the level of utility lost - or in a particular sense "the amount of pain" - that is incurred when risk $\widetilde{\varepsilon}$ is added to $x$. Since the individual is assumed to be risk averse in wealth, i.e. since $u_{11}<0$, we have $v(x, y)>0$.

Taking the derivative with respect to $y$ obtains $v_{2}(x, y)=u_{2}(x, y)-$ $E u_{2}(x+\widetilde{\varepsilon}, y)$. It follows from Jensen's inequality that $v_{2}(x, y) \leq 0 \forall(x, y)$ if

\footnotetext{
${ }^{8}$ Many additional two-attribute utility functions are discussed in Keeney and Raiffa (1976).

${ }^{9}$ An alternative proof for this case appears in Richard (1975). Also, we do not investigate the strength of correlation-averse behavior, which also would then examine measures of correlation aversion "in the small." A paper by Bommier (2005) offers one approach in this direction.
} 
and only if $u_{2}$ is convex in $x$. In an expected utility setting, this is equivalent to $u_{112} \geq 0$. But now $v_{2} \leq 0$ is equivalent to

$$
u(x, y)-E u(x+\widetilde{\varepsilon}, y) \leq u(x, y-c)-E u(x+\widetilde{\varepsilon}, y-c) \forall c>0 .
$$

Again, rearranging and multiplying by $1 / 2$ shows that this is equivalent to our lottery-preference definition of cross prudence in health.

A symmetric argument shows that cross prudence in wealth is equivalent to $u_{122} \geq 0$.

\subsection{Cross Temperance}

Taking the derivative of $v_{2}(x, y)$ above with respect to $y$ obtains $v_{22}(x, y)=$ $u_{22}(x, y)-E u_{22}(x+\widetilde{\varepsilon}, y)$. From Jensen's inequality, it follows that $v(x, y)$ is convex in $y, v_{22}(x, y) \geq 0 \forall(x, y)$, if and only if $u_{22}(x, y)$ is concave in $x$, i.e. if and only if $u_{1122}(x, y) \leq 0$.

Now consider a fixed risk $\widetilde{\delta}$, where $\widetilde{\delta}$ is independent of $\widetilde{\varepsilon}$. It follows that $v(x, y)-E v(x, y+\widetilde{\delta}) \leq 0$ if and only if $v(x, y)$ is convex in $y$, which we have just shown to be equivalent to $u_{1122}(x, y) \leq 0$. We complete the proof by expanding $v(x, y)$ :

$$
\begin{gathered}
0 \geq v(x, y)-E v(x, y+\widetilde{\delta}) \\
=[u(x, y)-E u(x+\widetilde{\varepsilon}, y)]-[E u(x, y+\widetilde{\delta})-E u(x+\widetilde{\varepsilon}, y+\widetilde{\delta})] .
\end{gathered}
$$

Rearranging and multiplying by $1 / 2$ shows that this is equivalent to our lottery-preference definition of cross temperance.

\subsection{Submodularity}

The lattice structure, described in the previous section, gives rise to submodularity of a preference functional defined over the lotteries. In particular, since expected utility is linear in the probabilities, we can think of the 
expected utility of the pair $(x+a, y+b)$ as a bivariate functional, where $(a, b) \in \Lambda \times \Gamma$ as defined previously. ${ }^{10}$ The fact that a 50-50 gamble between $(x+a, y+b)$ and $(x+A, y+B)$ is always weakly preferred to a 50-50 gamble between the meet and the join is then equivalent to saying that our lottery preference functional is submodular. ${ }^{11}$ Of course, this submodularity depends upon preferences exhibiting correlation aversion, cross prudence in wealth, cross prudence in health and cross temperance, as well as monotonicity and risk aversion for both wealth and health separately. ${ }^{12}$

\section{Applications}

Numerous examples already appear in which the sign of $u_{12}$ is significant in determining the results, see for example Rey and Rochet (2004). In this section, we provide a few applications based on intertemporal consumption choices, where utility within each period depends upon two arguments. We assume in all of the examples that $u_{1}>0, u_{2}>0, u_{11}<0$ and $u_{22}<0$, which is also sufficient for all of the appropriate second-order conditions to hold.

Although our interpretations in this paper have been based on preferences over simple 50-50 lotteries, we can extend the logic in an obvious way to

\footnotetext{
${ }^{10}$ Again we take some liberty with the notation here. More formally, we have a functional over the distribution functions for $x+a$ and $y+b$.

${ }^{11}$ A function $M$ is submodular over elements of a lattice if $M(\alpha)+M(\beta) \geq M(\alpha \vee \beta)+$ $M(\alpha \wedge \beta)$.

${ }^{12}$ Although we do not pursue it in the current paper, one can extend the results here to higher dimensions along lines similar to those in Eeckhoudt and Schlesinger (2006). For example, we can redefine $\Lambda$ in section 3.3 as a set containing two lotteries:

(i) lottery $A$, which is a $50-50$ chance of $-k$ or $\widetilde{\varepsilon}$ and

(ii) lottery $a$, which is a $50-50$ chance of $-k+\widetilde{\varepsilon}$ or zero. Lotteries $A$ and $a$ then become our two "harms." From Eeckhoudt and Schlesinger (2006), we know that $(x+A, y)$ is weakly preferred to $(x+a, y)$ for all $x$ and for all $y$, if and only if $u_{111}(x, y) \geq 0$. Determining when utility is submodular for this lattice structure will determine the signs of $u_{1112}$ and $u_{11122}$.
} 
intertemporal choices for which intratemporal utility is the same within each period. For example, we know that $u_{11}<0$ implies a type of risk aversion in the first attribute $x$, but we also know that $u_{11}<0$ induces a preference for "smoothing" the level of $x$ over time. In such as setting, correlation aversion can be interpreted in a type of time-series sense. The correlation averse individual prefers the time sequence $[(x-k, y) \longrightarrow(x, y-c)]$ to the time sequence $[(x, y) \longrightarrow(x-k, y-c)]$. The examples below are in this spirit.

Suppose that the consumer wishes to maximize her utility of consumption of wealth and of health over two dates. We will assume that the optimization problem is to choose a level of savings $s$ to

$$
\max U(s)=u(x-s, y)+\beta u(x+s(1+r), y),
$$

where $x$ is the consumer's income in each period, $r$ is a risk-free rate of interest earned on any savings, and $\beta$ is a personal discount factor for future utility. In the simplest case, we set $\beta=(1+r)^{-1}=1$. This yields the first order-condition

$$
U^{\prime}(s)=-u_{1}(x-s, y)+u_{1}(x+s, y)=0,
$$

yielding a solution of $s^{*}=0$. The second order condition is trivially satisfied. Although (5) does not refer to a lottery per se, note that multiplying $U(s)$ by $1 / 2$ would allow for such an interpretation. In other words, our lottery example can be easily interpreted as a two-period optimization problem.

\subsection{Correlation Aversion}

Suppose that at date $t=1$ the consumer knows her health will deteriorate by an amount $c>0$. The maximization problem (5) is then transformed into

$$
\max U(s)=u(x-s, y)+u(x+s, y-c) .
$$


Evaluating the derivative of $U$ at the previous optimum, $s^{*}=0$, shows that $U^{\prime}\left(s^{*}\right)>0$ whenever $u_{12}(x, y)<0 \forall(x, y)$. Since $U$ is concave in $s$, it follows that savings will increase in this case. Thus, correlation aversion is equivalent to an additional savings motive for an individual whose health is declining over time.

\subsection{Cross Prudence in Wealth}

Suppose now that at date $t=1$ the consumer does not know what her health status will be. In particular, she believes it will remain at level $y$, but there is some risk, which we model via the zero-mean random variable $\widetilde{\delta}$. Her savings objective is now to

$$
\max U(s)=u(x-s, y)+E u(x+s, y+\widetilde{\delta})
$$

Again evaluating the derivative of $U$ at the previous optimum $s^{*}=0$ shows that $U^{\prime}\left(s^{*}\right) \geq 0$ whenever $u_{122}(x, y) \geq 0 \forall(x, y)$. In this case, the consumer who perceives her health in the next period to be risky, will save more today. Thus, cross prudence in wealth is equivalent to a motive for precautionary savings to protect oneself against future health risk. ${ }^{13}$

\subsection{Cross Prudence in Health}

Here we consider an example of tertiary prevention. ${ }^{14}$ As a base case, we assume that the individual has a fixed level of income in each period $x$. The individual has a chronic illness that causes health to deteriorate at date

\footnotetext{
${ }^{13}$ We should point out, however, that this effect is not due to any motive to finance health treatment. In that case, both wealth and health would be affected at date $t=1$ if health is poor. Rather, the cross-prudent individual saves more only in an attempt to substitute higher wealth, i.e. more material goods, to compensate for possibly deteriorating health.

${ }^{14}$ Tertiary prevention activities involve treating an established disease or chronic illness in an attempt to minimize the future negative health effects of the disease or illness. See, U.S. Preventive Services Task Force (1996).
} 
$t=1$ from $y$ to $y-c$. At date $t=0$, the individual can "invest" some of her current health in such tertiary care. We assume that the monetary cost of this preventative care is negligible. The care itself lowers the status of current health, for example via side effects, but it mitigates the future negative effects of the illness at date $t=1$. In particular, let $z$ denote the level of care chosen, where such a choice lowers the current health status from level $y$ to $y-z$. In return, such a choice increases the status of future health from $y-c$ to $y-c+\theta z$, where $\theta>0$ reflects the effect per "unit" of tertiary prevention.

The individual's decision problem is thus

$$
\max U(z)=u(x, y-z)+u(x, y-c+\theta z) .
$$

The first-order condition for this optimization is

$$
U^{\prime}(z)=-u_{2}(x, y-z)+\theta u_{2}(x, y-c+\theta z)=0,
$$

which holds at some care level $z^{*}$.

We now suppose that income in the second period becomes risky and equals $x+\widetilde{\varepsilon}$, where $E \widetilde{\varepsilon}=0$. It follows in a straightforward manner that the optimal care level $z^{*}$ will increase whenever

$$
E u_{2}(x+\widetilde{\varepsilon}, y-c+\theta z)>u_{2}(x, y-c+\theta z),
$$

which will hold whenever $u_{2}$ is convex in $x$, i.e. whenever $u_{112}>0$. In this case, the individual who is cross prudent in health will "invest" more in tertiary preventative care at date $t=0$ in order to increase her health status at date $t=1$. This increased health status helps her to cope with the "pain" of risky income at date $t=1$. 


\subsection{Cross Temperance}

For this example, we consider an individual who is cross temperate $\left(u_{1122}<0\right)$ and for whom $u_{122}$ is of uniform sign throughout the relevant range of wealth and health levels. That is, either $u_{122}>0$ (cross prudence in wealth) or $u_{122}<0$ (cross imprudence in wealth) holds for all relevant wealth and health levels. As a base case, suppose for now that the individual's health is the same in both periods. The individual still has an income of $x$ in each period, but now has an additional lifetime net asset value of $\widetilde{\varepsilon}, E \widetilde{\varepsilon}=0$, where $\varepsilon>0$ indicates a net asset and $\varepsilon<0$ indicates a net liability. The individual must decide at date $t=0$, but before $\widetilde{\varepsilon}$ is realized, how to distribute the $\widetilde{\varepsilon}$-risk over the two periods. This consumer's initial objective is to choose $\alpha \in[0,1]$ to

$$
\max U(\alpha)=E u(x+\alpha \widetilde{\varepsilon}, y)+E u(x+(1-\alpha) \widetilde{\varepsilon}, y) .
$$

The first order condition is

$$
U^{\prime}(\alpha)=E\left[u_{1}(x+\alpha \widetilde{\varepsilon}, y) \widetilde{\varepsilon}\right]-E\left[u_{1}(x+(1-\alpha) \widetilde{\varepsilon}, y) \widetilde{\varepsilon}\right]=0 .
$$

Since $U$ is concave in $\alpha$ (assuming that $u_{11}<0$ ), the first-order condition in-

dicates a unique optimum at $\alpha^{*}=\frac{1}{2}$ : the individual chooses to fully diversify the $\widetilde{\varepsilon}$-risk over the two time periods.

Now suppose that we introduce the zero-mean health risk $\widetilde{\delta}$ at date $t=1$. The new objective is thus

$$
\max U(\alpha)=E u(x+\alpha \widetilde{\varepsilon}, y)+E u(x+(1-\alpha) \widetilde{\varepsilon}, y+\widetilde{\delta}) .
$$

Evaluating $U^{\prime}(\alpha)$ at the old optimal value of $\alpha^{*}=\frac{1}{2}$, we obtain

$$
U^{\prime}\left(\frac{1}{2}\right)=E\left[u_{1}\left(x+\frac{1}{2} \widetilde{\varepsilon}, y\right) \widetilde{\varepsilon}\right]-E\left[u_{1}\left(x+\frac{1}{2} \widetilde{\varepsilon}, y+\widetilde{\delta}\right) \widetilde{\varepsilon}\right] .
$$

The individual will increase $\alpha^{*}$ and bear more of the wealth-risk in the first 
period whenever $U^{\prime}\left(\frac{1}{2}\right)>0$.

Define $H(x, y) \equiv E\left[u_{1}\left(x+\frac{1}{2} \widetilde{\varepsilon}, y\right) \widetilde{\varepsilon}\right]$. Then $U^{\prime}\left(\frac{1}{2}\right)>0$ will follow if $H$ is concave in $y$, i.e. $H_{22}(x, y)<0$. But, since $u_{122}$ is assumed to be of uniform sign and to be decreasing in $x$, we obtain the following inequality:

$$
\begin{gathered}
H_{22}(x, y)=\int_{-\infty}^{0} u_{122}\left(x+\frac{1}{2} \varepsilon, y\right) \varepsilon d F(\varepsilon)+\int_{0}^{+\infty} u_{122}\left(x+\frac{1}{2} \varepsilon, y\right) \varepsilon d F(\varepsilon) \\
<\int_{-\infty}^{0} u_{122}(x, y) \varepsilon d F(\varepsilon)+\int_{0}^{+\infty} u_{122}(x, y) \varepsilon d F(\varepsilon)=0 .
\end{gathered}
$$

Thus, the cross-temperate individual modifies her behavior and accepts a larger share of the $\widetilde{\varepsilon}$-risk in the first period.

\section{Conclusion}

We have shown how the signs of various cross derivatives of a multivariate utility function are equivalent to a particular type of simple lottery preference. The structure of the lotteries is particularly simple, with all of our lotteries being simple 50-50 binary lotteries. The simplicity of the structure would seem to make them quite adaptable to laboratory experiments.

Within the expected-utility framework, there has been much literature that depends upon the signs of these cross derivatives. Our results give a lottery-preference equivalent to signing these cross derivatives. Since our lotteries are not defined unique to the expected-utility preference functional, other decision-theoretic paradigms can be compared to the concepts.

Our goal in the paper is not to claim that the concepts we defined correlation aversion, cross prudence and cross temperance - are in any way inherent traits of most consumers. Indeed, for readers who doubt that the lottery preference orderings defined by these concepts, or the reverse orderings, will always hold, our results show that it is not possible for the cross partial derivatives to be of a consistent sign. 


\section{References}

[1] Atkinson, Anthony and Bourguignon, François, (1982). "The Comparison of Multidimensional Distributions on Economic Status." Review of Economic Studies 49, 181-201.

[2] Bleichrodt, Han; Crainich, David and Eeckhoudt, Louis, (2003). "The Effect of Comorbidities on Treatment Decisions." Journal of Health Economics 22, 805-20.

[3] Bommier, Antoine, (2005). "Risk Aversion, Intertemporal Elasticity of Substitution and Correlation Aversion." Unpublished Working Paper, University of Toulouse.

[4] Dardanoni, Valentino, (1988). "Optimal Choices under Uncertainty: The Case of Two-Argument Utility Functions." Economic Journal 98, 429-50.

[5] Dardanoni, Valentino and Wagstaff, Adam, (1990). "Uncertainty and the Demand for Medical Care." Journal of Health Economics 9, 23-38.

[6] de Finetti, B., (1952). "Sulla Preferibilitia." Giornal degli Economisti e Annali di Economia 11, 685-709.

[7] Drèze, Jacques and Modigliani, Franco, (1972). "Consumption Decisions under Uncertainty." Journal of Economic Theory 5, 308-35.

[8] Eisner, Robert and Strotz, R., (1961). "Flight Insurance and the Theory of Choice." Journal of Political Economy 69, 355-68.

[9] Eaton, Jonathan and Rosen, Harvey, (1980). "Labor Supply, Uncertainty and Efficient Taxation." Journal of Public Economics 14, 365-74.

[10] Eeckhoudt, Louis and Schlesinger, Harris, (2006). "Putting Risk in its Proper Place." American Economic Review 96, 280-289. 
[11] Epstein, Larry G. and Tanny, S. M., (1980). "Increasing Generalized Correlation: A Definition and Some Economic Consequences." Canadian Journal of Economics 13, 16-34.

[12] Evans, William N. and Viscusi, W. Kip, (1991). "Estimation of StateDependent Utility Functions using Survey Data." Review of Economics and Staistics 73, 94-104.

[13] Friedman, Milton and Savage, Leonard J., (1948). "The Utility Analysis of Choices Involving Risk." Journal of Political Economy 56, 279-304.

[14] Keeney, Ralph L. and Raiffa, Howard, (1976). Decisions with Multiple Objectives: Preferences and Value Tradeoffs, New York: John Wiley and Sons. [Reprinted by Cambridge University Press, 1993.]

[15] Kimball, Miles S., (1990) "Precautionary Savings in the Small and in the Large." Econometrica 58, 53-73.

[16] Kimball, Miles S., (1992). "Precautionary Motives for Holding Assets." in The New Palgrave Dictionary of Money and Finance. P. Newman, M. Milgate, and J. Falwell, eds. London: MacMillan.

[17] Kimball, M.S., (1993), "Standard Risk Aversion," Econometrica 61, 589611.

[18] Leland, Hayne E., (1968). "Saving and Uncertainty: The Precautionary Demand for Saving." Quarterly Journal of Economics 82, 465-73.

[19] Moyes, P., (1999). "Comparisons of Heterogeneous Distributions and Dominance Criteria." Economie et Prévision 138, 125-46.

[20] Rey, Béatrice and Rochet, Jean-Charles, (2004). "Health and Wealth: How do They Affect Individual Preferences?" Geneva Papers on Risk and Insurance Theory 29, 43-54. 
[21] Richard, Scott, (1975). "Multivariate Risk Aversion, Utility Independence and Separable Utility Functions." Management Science 22, 12-21.

[22] Sandmo, Agnar, (1970). "The Effect of Uncertainty on Saving Decisions." Review of Economic Studies 37, 353-60.

[23] Trannoy, Alain (2005). "Multidimensional Egalitarianism and the Dominance Approach: A Lost Paradise." in F. Farina and E. Savaglio (eds.), Inequality and Economic Integration. London: Routledge.

[24] Tressler, J. H. and Menezes, Carmen F., (1980). "Labor Supply and Wage Rate Uncertainty." Journal of Economic Theory 23, 425-36.

[25] U.S. Preventive Services Task Force, (1996). Guide to Clinical Preventive Services, 2nd Edition. Washington, DC: U.S. Department of Health and Human Services.

[26] Viscusi, W. Kip and Evans, William N., (1990). "Utility Functions that Depend on Health Status: Estimates and Economic Implications." American Economic Review 80, 353-74.

[27] Wagstaff, Adam; Paci P. and van Doorslaer, E., (1991). "On the Measurement of Inequalities in Health." Social Science and Medicine 33, $545-57$. 


\title{
CESifo Working Paper Series
}

\author{
(for full list see www.cesifo-group.de)
}

1732 Kerstin Bernoth and Guntram B. Wolff, Fool the Markets? Creative Accounting, Fiscal Transparency and Sovereign Risk Premia, May 2006

1733 Emmanuelle Auriol and Pierre M. Picard, Government Outsourcing: Public Contracting with Private Monopoly, May 2006

1734 Guglielmo Maria Caporale and Luis A. Gil-Alana, Modelling Structural Breaks in the US, UK and Japanese Unemployment Rates, May 2006

1735 Emily J. Blanchard, Reevaluating the Role of Trade Agreements: Does Investment Globalization Make the WTO Obsolete?, May 2006

1736 Per Engström and Bertil Holmlund, Tax Evasion and Self-Employment in a High-Tax Country: Evidence from Sweden, May 2006

1737 Erkki Koskela and Mikko Puhakka, Cycles and Indeterminacy in Overlapping Generations Economies with Stone-Geary Preferences, May 2006

1738 Saku Aura and Thomas Davidoff, Supply Constraints and Housing Prices, May 2006

1739 Balázs Égert and Ronald MacDonald, Monetary Transmission Mechanism in Transition Economies: Surveying the Surveyable, June 2006

1740 Ben J. Heijdra and Ward E. Romp, Ageing and Growth in the Small Open Economy, June 2006

1741 Robert Fenge and Volker Meier, Subsidies for Wages and Infrastructure: How to Restrain Undesired Immigration, June 2006

1742 Robert S. Chirinko and Debdulal Mallick, The Elasticity of Derived Demand, Factor Substitution and Product Demand: Corrections to Hicks' Formula and Marshall's Four Rules, June 2006

1743 Harry P. Bowen, Haris Munandar and Jean-Marie Viaene, Evidence and Implications of Zipf's Law for Integrated Economies, June 2006

1744 Markku Lanne and Helmut Luetkepohl, Identifying Monetary Policy Shocks via Changes in Volatility, June 2006

1745 Timo Trimborn, Karl-Josef Koch and Thomas M. Steger, Multi-Dimensional Transitional Dynamics: A Simple Numberical Procedure, June 2006

1746 Vivek H. Dehejia and Yiagadeesen Samy, Labor Standards and Economic Integration in the European Union: An Empirical Analysis, June 2006 
1747 Carlo Altavilla and Paul De Grauwe, Forecasting and Combining Competing Models of Exchange Rate Determination, June 2006

1748 Olaf Posch and Klaus Waelde, Natural Volatility, Welfare and Taxation, June 2006

1749 Christian Holzner, Volker Meier and Martin Werding, Workfare, Monitoring, and Efficiency Wages, June 2006

1750 Steven Brakman, Harry Garretsen and Charles van Marrewijk, Agglomeration and Aid, June 2006

1751 Robert Fenge and Jakob von Weizsäcker, Mixing Bismarck and Child Pension Systems: An Optimum Taxation Approach, June 2006

1752 Helge Berger and Michael Neugart, Labor Courts, Nomination Bias, and Unemployment in Germany, June 2006

1753 Chris van Klaveren, Bernard van Praag and Henriette Maassen van den Brink, A Collective Household Model of Time Allocation - a Comparison of Native Dutch and Immigrant Households in the Netherlands, June 2006

1754 Marko Koethenbuerger, Ex-Post Redistribution in a Federation: Implications for Corrective Policy, July 2006

1755 Axel Dreher, Jan-Egbert Sturm and Heinrich Ursprung, The Impact of Globalization on the Composition of Government Expenditures: Evidence from Panel Data, July 2006

1756 Richard Schmidtke, Private Provision of a Complementary Public Good, July 2006

1757 J. Atsu Amegashie, Intentions and Social Interactions, July 2006

1758 Alessandro Balestrino, Tax Avoidance, Endogenous Social Norms, and the Comparison Income Effect, July 2006

1759 Øystein Thøgersen, Intergenerational Risk Sharing by Means of Pay-as-you-go Programs - an Investigation of Alternative Mechanisms, July 2006

1760 Pascalis Raimondos-Møller and Alan D. Woodland, Steepest Ascent Tariff Reforms, July 2006

1761 Ronald MacDonald and Cezary Wojcik, Catching-up, Inflation Differentials and Credit Booms in a Heterogeneous Monetary Union: Some Implications for EMU and new EU Member States, July 2006

1762 Robert Dur, Status-Seeking in Criminal Subcultures and the Double Dividend of ZeroTolerance, July 2006

1763 Christa Hainz, Business Groups in Emerging Markets - Financial Control and Sequential Investment, July 2006 
1764 Didier Laussel and Raymond Riezman, Fixed Transport Costs and International Trade, July 2006

1765 Rafael Lalive, How do Extended Benefits Affect Unemployment Duration? A Regression Discontinuity Approach, July 2006

1766 Eric Hillebrand, Gunther Schnabl and Yasemin Ulu, Japanese Foreign Exchange Intervention and the Yen/Dollar Exchange Rate: A Simultaneous Equations Approach Using Realized Volatility, July 2006

1767 Carsten Hefeker, EMU Enlargement, Policy Uncertainty and Economic Reforms, July 2006

1768 Giovanni Facchini and Anna Maria Mayda, Individual Attitudes towards Immigrants: Welfare-State Determinants across Countries, July 2006

1769 Maarten Bosker and Harry Garretsen, Geography Rules Too! Economic Development and the Geography of Institutions, July 2006

1770 M. Hashem Pesaran and Allan Timmermann, Testing Dependence among Serially Correlated Multi-category Variables, July 2006

1771 Juergen von Hagen and Haiping Zhang, Financial Liberalization in a Small Open Economy, August 2006

1772 Alessandro Cigno, Is there a Social Security Tax Wedge?, August 2006

1773 Peter Egger, Simon Loretz, Michael Pfaffermayr and Hannes Winner, Corporate Taxation and Multinational Activity, August 2006

1774 Jeremy S.S. Edwards, Wolfgang Eggert and Alfons J. Weichenrieder, The Measurement of Firm Ownership and its Effect on Managerial Pay, August 2006

1775 Scott Alan Carson and Thomas N. Maloney, Living Standards in Black and White: Evidence from the Heights of Ohio Prison Inmates, 1829 - 1913, August 2006

1776 Richard Schmidtke, Two-Sided Markets with Pecuniary and Participation Externalities, August 2006

1777 Ben J. Heijdra and Jenny E. Ligthart, The Transitional Dynamics of Fiscal Policy in Small Open Economies, August 2006

1778 Jay Pil Choi, How Reasonable is the 'Reasonable' Royalty Rate? Damage Rules and Probabilistic Intellectual Property Rights, August 2006

1779 Ludger Woessmann, Efficiency and Equity of European Education and Training Policies, August 2006

1780 Gregory Ponthiere, Growth, Longevity and Public Policy, August 2006 
1781 Laszlo Goerke, Corporate and Personal Income Tax Declarations, August 2006

1782 Florian Englmaier, Pablo Guillén, Loreto Llorente, Sander Onderstal and Rupert Sausgruber, The Chopstick Auction: A Study of the Exposure Problem in Multi-Unit Auctions, August 2006

1783 Adam S. Posen and Daniel Popov Gould, Has EMU had any Impact on the Degree of Wage Restraint?, August 2006

1784 Paolo M. Panteghini, A Simple Explanation for the Unfavorable Tax Treatment of Investment Costs, August 2006

1785 Alan J. Auerbach, Why have Corporate Tax Revenues Declined? Another Look, August 2006

1786 Hideshi Itoh and Hodaka Morita, Formal Contracts, Relational Contracts, and the Holdup Problem, August 2006

1787 Rafael Lalive and Alejandra Cattaneo, Social Interactions and Schooling Decisions, August 2006

1788 George Kapetanios, M. Hashem Pesaran and Takashi Yamagata, Panels with Nonstationary Multifactor Error Structures, August 2006

1789 Torben M. Andersen, Increasing Longevity and Social Security Reforms, August 2006

1790 John Whalley, Recent Regional Agreements: Why so many, why so much Variance in Form, why Coming so fast, and where are they Headed?, August 2006

1791 Sebastian G. Kessing and Kai A. Konrad, Time Consistency and Bureaucratic Budget Competition, August 2006

1792 Bertil Holmlund, Qian Liu and Oskar Nordström Skans, Mind the Gap? Estimating the Effects of Postponing Higher Education, August 2006

1793 Peter Birch Sørensen, Can Capital Income Taxes Survive? And Should They?, August 2006

1794 Michael Kosfeld, Akira Okada and Arno Riedl, Institution Formation in Public Goods Games, September 2006

1795 Marcel Gérard, Reforming the Taxation of Multijurisdictional Enterprises in Europe, a Tentative Appraisal, September 2006

1796 Louis Eeckhoudt, Béatrice Rey and Harris Schlesinger, A Good Sign for Multivariate Risk Taking, September 2006 